\title{
The work patterns of consultant psychiatrists
}

\author{
REVISITING... HOW CONSULTANTS MANAGE THEIR TIME

\section{Judith Harrison}

\begin{abstract}
Much has changed in the National Health Service in the UK in the past 10 years and consultant roles need to adapt accordingly. This article describes the drivers for change in consultant roles, including enhanced roles for other mental health professionals, increased expectations of users and carers, changes in junior doctors' work patterns and the new consultant contract. The recommendations of the report on New Ways of Working for Psychiatrists are reviewed, with suggestions for changes in the consultant role in out-patient clinics, community teams and acute care. Enhanced roles for other mental health professionals and the increasing trend to specialisation are also discussed.
\end{abstract}

Over a decade ago Francis Creed wrote in this journal about how consultants manage their time (Creed, 1995). The article was based on a theoretical model proposed by Watson $(1985,1986)$ linking the use of consultant clinic time with models of service delivery. Creed included the following recommendations: consultants should review their out-patient clinics to establish their precise purpose and plan packages of care (in terms of time and treatment skills required) that allow an estimate of the resources spent on each patient. Much has changed in the National Health Service (NHS) since then: how have consultants' work patterns altered and to what extent have Creed's recommendations been met?

\section{Box 1 Drivers for change}

- High levels of stress and burnout among psychiatrists

- Increasing expertise and autonomy of other mental health professionals

- Increased expectations of users and carers

- Changes in junior doctors' working patterns

- The new consultant contract
During the late 1990s, the experience of many consultant psychiatrists in the UK was of increased work pressures and gradual erosion in job satisfaction. A series of reports documented increased case-loads (Tyrer et al, 2001), high stress levels (Rathod et al, 2000) and experienced psychiatrists taking early retirement because of excessive workloads, lack of resources and increased bureaucracy (Kendell \& Pearce, 1997). Recruitment and retention were increasingly difficult (Pidd, 2003). Could more be done to make the consultant role attractive, rewarding and sustainable?

\section{Drivers for change (Box 1) \\ Increasing expertise and autonomy of other mental health professionals}

To attract and retain a skilled mental health workforce, staff need to feel valued and to have appropriate opportunities for career development. Hierarchical structures, with doctors 'in charge', are increasingly unacceptable to other mental health professionals, who expect greater autonomy and sharing of responsibility within clinical teams. Mental health workers from all disciplines now undertake postgraduate studies with a view to developing expert practice, and are well placed to take on a variety of traditionally medical roles.

Judith Harrison is a consultant and honorary lecturer in general adult psychiatry (Manchester Mental Health and Social Care Trust, Chorlton House, 70 Manchester Road, Chorlton, Manchester M21 9UN, UK. Email : judy.harrison@mhsc.nhs.uk) and has organised seminars and workshops throughout the north-west of England on consultant roles. She has been a member of the national steering group for New Ways of Working for Psychiatrists and an advisor to the National Institute for Mental Health in England (NIMHE) North West Development Centre. 
These changes mirror those occurring in many other branches of medicine. Specialist nurse posts already exist in many disciplines and specific proposals have been published for the development of surgical care practitioners (Department of Health, 2005) and physician assistants (Department of Health, 2006a), similar to those seen in the USA.

\section{Expectations of users and carers}

The traditional consultant model involves brief consultations with large numbers of patients, often in the presence of other staff or students, and little scheduled time available for carers. With the advent of more consumerist models of healthcare, patients and carers rightly expect more time with psychiatrists and other staff in order to participate in decision-making as equal partners.

\section{Changes in junior doctors' working patterns}

The European Working Time Directive has placed strict limits on the hours junior doctors can work, resulting in the widespread adoption of shift working. Although the reduction in juniors' hours is welcome, the net effect is reduced availability of junior doctors in normal working hours. Unless this is approached as an opportunity to rethink traditional medical roles, it is likely that the increased daytime workload will fall predominantly to consultants. The major changes in training for junior doctors currently being implemented through Modernising Medical Careers (Department of Health, 2004) will also influence future training roles for consultants.

\section{New consultant contract}

In 2004, a new contract for consultants was introduced for the first time since the inception of the NHS. In agreeing on existing activity levels, consultants were asked to complete a diary exercise, similar to that described by Creed (1995), and use this as the basis of negotiations for any changes in job plan. As recommended in Creed's original article, the main aims of the contract were to properly quantify and reward the work consultants do, while at the same time introducing a link to management objectives for local services. Although evidence for resulting major change in consultants' work patterns is lacking at a national level (Williams \& Buchan, 2006), there are examples of consultant psychiatrists using the contract to agree changes that make their own working lives more rewarding and improve local services (Hampson, 2003; Simpson \& Farrimond, 2006).

\section{A way forward}

Recognising the pressure for change, the Royal College of Psychiatrists, the British Medical Association and the Department of Health organised two national conferences to consider the future role of consultant psychiatrists. Many common concerns were identified and a number of potential solutions were proposed, as described in the conference report (National Working Group on New Roles for Psychiatrists, 2004). A national steering group was established to review consultant roles, with an emerging workstream referred to as New Ways of Working for consultant psychiatrists. The report of the national steering group (Care Services Improvement Partnership et al, 2005) includes details of many innovative proposals for changes to consultant roles (Box 2), some of which are summarised below.

The steering group's report is of relevance to all psychiatrists but recognises that the role of the consultant has developed in different ways across the specialties, particularly in relation to shared responsibility within teams. Similarly, although the report is focused on mental health services in England, many of the suggestions for change in consultant roles are applicable across the UK.

\section{Changes in policy framezwork}

Any shift in consultant roles and responsibilities needs to be supported by corresponding changes in the NHS strategic framework. Several policy reviews have already been undertaken: the Royal College of Psychiatrists has adopted a new report on roles and responsibilities of the consultant in general adult psychiatry (Royal College of Psychiatrists, 2006) and new guidance on the employment of consultant psychiatrists has been agreed jointly between the College and the NHS Confederation

\section{Box 2 Suggested areas for developing the} consultant role

- Changes in policy framework

- Encouraging teamwork and shared responsibilities

- Reviewing consultants' work patterns, including out-patient clinics

- Specialisation by treatment setting (e.g. inpatient, out-patient)

- Specialisation by function (e.g. assertive outreach)

- Developing enhanced roles for other professionals 
Table 1 Analysis of consultants' work patterns

\begin{tabular}{|c|c|c|c|c|c|}
\hline \multicolumn{2}{|c|}{ Workload pattern } & \multicolumn{2}{|c|}{ Ambiguity of role } & \multicolumn{2}{|c|}{ Perceived support } \\
\hline 'Progressive' & 'Traditional' & 'Progressive' & 'Traditional' & 'Progressive' & 'Traditional' \\
\hline $\begin{array}{l}\text { Lower personal } \\
\text { case-load } \\
\text { Fewer fixed } \\
\text { sessions } \\
\text { Shared responsi- } \\
\text { bility in team } \\
\text { More time for: } \\
\text { - supporting } \\
\text { other pro- } \\
\text { fessionals } \\
\text { - emergency } \\
\text { work } \\
\text { - professional } \\
\text { development }\end{array}$ & $\begin{array}{l}\text { High personal } \\
\text { case-load } \\
\text { High number of } \\
\text { fixed sessions } \\
\text { Little sharing of } \\
\text { responsibility } \\
\text { Little time for: } \\
\text { - supporting } \\
\text { others } \\
\text { - emergency } \\
\text { work } \\
\text { - professional } \\
\text { development }\end{array}$ & $\begin{array}{l}\text { Low number of } \\
\text { direct referrals } \\
\text { from GPs } \\
\text { Low level of } \\
\text { isolation } \\
\text { Low levels of role } \\
\text { conflict } \\
\text { High reliance } \\
\text { on other team } \\
\text { members }\end{array}$ & $\begin{array}{l}\text { Separate referral } \\
\text { routes to doctor } \\
\text { and team } \\
\text { Feelings of } \\
\text { isolation } \\
\text { Sense of conflict- } \\
\text { ing personal roles } \\
\text { Little reliance on } \\
\text { others }\end{array}$ & $\begin{array}{l}\text { High levels of } \\
\text { perceived support } \\
\text { from team, other } \\
\text { consultants, trust } \\
\text { managers }\end{array}$ & $\begin{array}{l}\text { Low levels of } \\
\text { perceived support } \\
\text { from others }\end{array}$ \\
\hline
\end{tabular}

(Care Services Improvement Partnership et al, 2005); the latter includes the General Medical Council's clarification on the limits of consultant responsibility when working in multidisciplinary teams with distributed responsibility.

\section{Reviewing consultants' work patterns}

Kennedy \& Griffiths (2001) analysed the work patterns of 26 consultant psychiatrists and described a wide range of working styles and associated pressures. Building on this work, the Royal College of Psychiatrists' Research Unit carried out a detailed postal survey of work patterns among a random sample of 185 consultant psychiatrists across the UK (Pajak et al, 2003).

Three work-role scales (workload pattern, ambiguity of role and perceived support) were created for the study and participants' scores on these scales were used to categorise them as having a 'progressive' or 'traditional' approach (Table 1). Scores on the work-role scales were then compared with self-reported stress using the General Health Questionnaire (GHQ). Twenty-five per cent of respondents scored above the caseness threshold on the GHQ (compared with $17 \%$ of the general population) and $17 \%$ of respondents reported high burnout levels, higher than average for all mental health workers. Higher scores on the three work-role scales were strongly interrelated and were associated with lower GHQ scores, confirming the findings of Kennedy \& Griffiths (2001) that more progressive work patterns appear to be less stressful and more sustainable. How can consultants be helped to change existing work patterns?

\section{Adopting a team approach}

The philosophy of the New Ways of Working approach has been summarised as:

'using the skills, knowledge and experience of consultant psychiatrists to best effect by concentrating on service users with the most complex needs, acting as a consultant to multidisciplinary teams, promoting distributed responsibility and leadership across teams to achieve a cultural shift in services' (Care Services Improvement Partnership et al, 2005: p. 5).

Suggestions for achieving this include the adoption of a single referral mechanism to multidisciplinary teams, rather than a separate out-patient referral route, some type of triage so that consultants are not usually the first point of contact with secondary care and a review of case-loads to allow consultants to focus on a smaller number of complex cases while having flexible time available to respond to crises and support other team members.

Although most consultants work in multidisciplinary mental health teams, relatively little has been written about the structure and function of these teams or doctors' roles within them. In a national survey of the organisation and operation of community mental health teams in England, Onyett et al $(1994,1995)$ found that most teams had a clearly identified team manager, but that operational decisions such as which patients were eligible or allocation of cases were often taken by the team as a whole. The authors commented that 'ultimate responsibility for management tasks remains dispersed or undefined within the team, with little involvement from outside managers' (Onyett et al, 1995: p. 11). While most teams had at least some sessional input from consultant psychiatrists, very 
few considered the consultant psychiatrist to be the clinical leader or manager, and clinical supervision was rarely provided by consultants. If doctors are not directly involved in the day-to-day management of teams, greater understanding is needed of other ways in which they can contribute positively, for example through teamwork, strategic direction and leadership.

These issues have been revisited through the Creating Capable Teams approach, developed as part of the New Ways of Working programme (Department of Health, 2007). This provides a 3-day 'off-the-shelf' workshop to enable existing multidisciplinary teams to review their structure, function and skills mix. Although the role of the psychiatrist is not explicitly addressed, all team members are asked to review their current role and consider ways of redefining roles to better meet the needs of service users and carers.

\section{Reviewing out-patient clinics}

As Creed outlined in his article, much of the fixed clinical time in the consultant's week is accounted for by out-patient clinics, yet we still know relatively little about how this time is spent. The New Ways of Working report (Care Services Improvement Partnership et al, 2005) contains an out-patient audit tool providing much greater detail about each contact. Duration and purpose of contact are recorded according to 11 categories (Box 3 ). Doctors are also asked to indicate whether the intervention could have been undertaken by a different mental health professional and whether anything could have been done to make the contact more efficient (e.g.

\section{Box 3 Categories of out-patient contact}

The following is a summary of the contact categories in the Bromley and Greenwich medical staff out-patient clinic audit tool

- New assessment

- Carer/family education/support

- Court report preparation

- Preparation of benefit and other reports

- Care planning meeting

- Crisis resolution

- Medication review

- Physical health check

- Reassurance/support

- Risk assessment and risk monitoring

- Therapy session

(Care Services Improvement Partnership et al, 2005: p. 109) availability of notes, blood tests). This information has been used to reduce the burden of routine followup clinic appointments and to transfer appropriate cases to other professionals.

The report also questions the need for traditional out-patient clinics. Some services have moved to a more consultative model, where doctors respond to crises or offer advice through other workers. This can be supplemented by clinics with a specific remit, for example medication review. Consultants adopting this approach report positive feedback from other team members and increased job satisfaction (Hampson, 2003). In other areas, aspects of traditional out-patient work have been taken on by other professionals, particularly specialist nurses.

\section{Reviewing consultant roles in acute care}

Much of the early work on consultant roles focused on community teams and out-patients, yet many consultants spend a considerable amount of time looking after patients who are in hospital. A detailed analysis of medical roles on the in-patient ward can also be helpful (e.g. ward round functions, routine administrative tasks), to ensure that consultants' time can be spent to best effect providing direct clinical care to the most unwell patients. In some areas, trusts are employing specialist nurses as part of a medical team, to take on traditionally medical roles such as medication histories and physical reviews. This team approach is likely to be of increasing importance as changes in junior doctors' working hours and training make it more difficult for them to ensure continuity of care in a ward setting.

\section{Specialisation}

Part of the pressure reported by consultant psychiatrists arises from working across several teams, for example in-patient, day hospital and community teams, responding to crises from each. Although some consultants value this approach and see the provision of continuity for patients as an important part of their role, others find the expectation that they can deal with all the problems arising from a particular geographical patch unsustainable. A more radical solution to this pressure has been the increasing trend for consultants to specialise, either by function or treatment location.

In England, the Department of Health (2000) has advocated the development of specialist mental health teams as an alternative to the generic community mental health team (CMHT) model in general adult psychiatry. All trusts are required to establish separate teams for assertive outreach, crisis resolution and early intervention in psychosis, 
and it is envisaged that these teams will all contain dedicated consultant posts, working solely with the new team (Department of Health, 2001). While consultants are wary of the fragmentation that may result from these changes, many welcome the opportunity for a more focused and varied role for psychiatrists (Harrison \& Traill, 2004).

A further extension of specialisation is to have dedicated in-patient and emergency consultants whose time is focused entirely on patients who are acutely unwell. Dratcu et al (2003) describe a model of this kind in inner London, and the New Ways of Working report (Care Services Improvement Partnership et al, 2005) gives a number of other examples of trusts adopting this approach. Potential benefits include a greater focus on the most unwell group of patients, allowing more frequent patient review and protected time for Mental Health Act work. This may in turn improve the quality of care for patients in hospital, increase morale among other in-patient staff and speed up throughput. However, organising services in this way does depend on a sufficient number of consultants being willing to work entirely on in-patient units and the sustainability of such posts might be questioned.

\section{Enhanced roles for other mental health professionals}

Other mental health professionals have contributed to the review of consultant roles described in the New Ways of Working report and have also been reviewing their own roles (Department of Health, 2006b). Although thenon-medical consultant role was envisaged as a career progression for experienced clinical staff who did not wish to become full-time managers, the requirements for these posts are set at a level that precludes many potential applicants and uptake has been relatively low. In response, many areas have developed a range of other enhanced roles such as specialist or advanced practitioner, some of which have a specific remit to include traditional medical roles.

One example of extended roles is non-medical prescribing, currently open to nurses and pharmacists (National Prescribing Centre et al, 2005). With the appropriate training and qualification, nonmedical prescribers can now prescribe the full range of medications, through either independent or supplementary prescribing. Accurate figures on the uptake of non-medical prescribing in mental health are difficult to obtain, but it appears that a few trusts have a considerable number of staff performing supplementary prescribing, whereas most have trained only a small number of nurses, relatively few of whom actually prescribe in practice (Brimblecombe et al, 2005).

\section{Future challenges}

The New Ways of Working initiative has encouraged all mental health professionals to examine and redefine their roles and has described a range of ways in which consultants can change their work patterns to be more sustainable and rewarding. Despite this, the work patterns of some consultants appear to be largely unchanged since Creed's original article (Creed, 1995) and there is a risk that the momentum for change will be lost in the press of other policy initiatives. What factors will influence the future role of the consultant?

It is my opinion that much of the work to date has been driven by a desire for change from psychiatrists themselves. More work needs to be done to establish what patients, carers, general practitioners and other team members most want from psychiatrists.

Recent mental health legislation in England (the Mental Health Act 2007) offers the opportunity to extend the responsible medical officer (RMO) role to other professional groups. However, the extent to which these responsibilities will be welcomed or taken up by others is not yet unclear.

Modernising Medical Careers will transform the way psychiatrists are trained. Its impact on consultant roles is not yet clear, but it is vital that changes in the medical workforce are linked to other workforce initiatives, especially where non-medical staff are expanding their role.

The role of the consultant psychiatrist appears to be at a crossroads in its development. Whether we choose to become increasingly specialised, whether we embrace the increased autonomy of other mental health professionals, whether we willingly share our legal rights and responsibilities, it is important for psychiatrists to be engaged in the debate in the interests of our patients and of our own morale and well-being.

\section{Declaration of interest}

None.

\section{References}

Brimblecombe, N., Parr, A. \& Gray, R. (2005) Medication and mental health nurses: developing new ways of working. Mental Health Practice, 8(5), 12-14.

Care Services Improvement Partnership/National Institute for Mental Health in England, Changing Workforce Programme \& Royal College of Psychiatrists (2005) New Ways of Working for Psychiatrists: Enhancing Effective, Person-Centred Services through New Ways of Working in Multidisciplinary and MultiAgency Contexts. Final Report 'But Not the End of the Story'. Department of Health.

Creed, F. (1995) How consultants manage their time. Advances in Psychiatric Treatment, 1, 65-70. Available as a free download from http:/ / apt.rcpsych.org 
Department of Health (2000) The NHS Plan: A Plan for Investment, A Plan for Reform. TSO (The Stationery Office).

Department of Health (2001) The Mental Health Policy Implementation Guide. Department of Health.

Department of Health (2004) Modernising Medical Careers: The Next Steps. The Future Shape of Foundation, Specialist and General Practice Training Programmes. Department of Health.

Department of Health (2005) The National Curriculum Framework for Surgical Care Practitioners: A Consultation Document. Department of Health.

Department of Health (2006a) The Competence and Curriculum Framework for the Physician Assistant. Department of Health.

Department of Health (2006b) From Values to Action: The Chief Nursing Officer's Review of Mental Health Nursing. Department of Health.

Department of Health (2007) Creating Capable Teams Approach: Best Practice Guidance to Support the Implementation of New Ways of Working and New Roles. Department of Health.

Dratcu, L., Grandison, A. \& Adkin, A. (2003) Acute hospital care in inner London: splitting from mental health services in the community. Psychiatric Bulletin, 27, 83-86.

Hampson, M. (2003) It just took a blank sheet of paper: changing the job plan of an adult psychiatrist. Psychiatric Bulletin, 27 309-311.

Harrison, J. \& Traill, B. (2004) What do consultants think about the development of specialist mental health teams? Psychiatric Bulletin, 28, 83-86.

Kendell, R. E. \& Pearce, A. (1997) Consultant psychiatrists who retired prematurely in 1995 and 1996. Psychiatric Bulletin, 21, 741-745.

Kennedy, P. \& Griffiths, H. (2001) General psychiatrists discovering new roles for a new era ... and removing work stress. British Journal of Psychiatry, 179, 283-285.

National Prescribing Centre, National Institute for Mental Health in England \& Department of Health (2005) Improving Mental Health Services by Extending the Role of Nurses in Prescribing and Supplying Medication: Good Practice Guide. NPC, NIHME \& Department of Health.

National Working Group on New Roles for Psychiatrists (2004) New Roles for Psychiatrists. British Medical Association. http:// www.dh.gov.uk/en/Publicationsandstatistics/Publications/ PublicationsPolicyAndGuidance/DH_4073490

Onyett, S., Heppleston, T. \& Bushnell, D. (1994) The Organization and Operation of Community Mental Health Teams in England: A National Survey. Sainsbury Centre for Mental Health.

Onyett, S., Pillinger, T. \& Muijen, M. (1995) Making Community Mental Health Teams Work: CMHTs and the People Who Work in Them. Sainsbury Centre for Mental Health.

Pajak, S., Mears, A., Kendall, T., et al (2003) Workload and Working Patterns in Consultant Psychiatrists. An Investigation into Occupational Pressure and Burdens. College Research Unit, Royal College of Psychiatrists.

Pidd, S. A. (2003) Recruiting and retaining psychiatrists. Advances in Psychiatric Treatment, 9, 405-411.

Rathod, S., Roy, L., Ramsay, M., et al (2000) A survey of stress in psychiatrists working in the Wessex region. Psychiatric Bulletin, 24, 133-136.

Royal College of Psychiatrists (2006) Roles and Responsibilities of the Consultant in General Adult Psychiatry (Council Report CR140). Royal College of Psychiatrists.

Simpson, C. \& Farrimond, P. (2006) New ways of working in the North Yorkshire Dales. Psychiatric Bulletin, 30, 65-66.

Tyrer, P., Al Muderis, O. \& Gulbrandsen, D. (2001) Distribution of case-load in community mental health teams. Psychiatric Bulletin, 25, 10-12.

Watson, J. P. (1985) Psychiatric manpower and the work of the consultant. Bulletin of the Royal College of Psychiatrists, 9, 170-173.

Watson, J. P. (1986) Calculating a district's psychiatric manpower Bulletin of the Royal College of Psychiatrists, 10, 334-337.

Williams, S. \& Buchan, J. (2006) Assessing the New NHS Consultant Contract - A Something for Something Deal? King's Fund.

\section{MCQs}

1 Traditional work patterns of consultants have been characterised by:

a high levels of specialisation

b small case-loads

c responsibility for all patients known to the team

d protected professional development time

e shared responsibility within teams.

2 Consultant time is used most effectively:

a if consultants see all new referrals

b if consultants operate separate referral routes into services

c if consultants contribute to a multidisciplinary assessment process

d if consultants see as many patients as possible in their clinics

e if other professionals discuss all their cases with the consultant.

\section{Non-medical prescribing:}

a gives all nurses the right to prescribe within their area of expertise

b applies only to nurses

c has been widely adopted in mental health

d does not require any formal training or qualification

e might be expected to work well in specific clinic settings, e.g. depot/clozapine clinics.

4 Junior doctor training in psychiatry:

a will be largely unaffected by Modernising Medical Careers

b has been largely unaffected by the European Working Time Directive

c is unlikely to change in the near future

$\mathrm{d}$ has moved to shift rotas in many areas

e now provides greater clinical support to consultants than in the past.

5 Consultant posts in general adult psychiatry:

a are likely to become more specialist in the future

b have been easy to recruit to in recent years

c are generally viewed as rewarding and sustainable

d will become less flexible with new College guidance on job descriptions

e cannot be improved by enhancing the role of other professionals.

\section{MCQ answers}

$\begin{array}{llllll}1 & & 2 & 3 & 4 & 5 \\ \text { a F } & \text { a F } & \text { a F } & \text { a F } & \text { a T } \\ \text { b F } & \text { b F } & \text { b F } & \text { b F } & \text { b F } \\ \text { c T } & \text { c T } & \text { c F } & \text { c F } & \text { c F } \\ \text { d F } & \text { d F } & \text { d F } & \text { d T } & \text { d F } \\ \text { e F } & \text { e F } & \text { e T } & \text { e F } & \text { e F }\end{array}$

